
y artistas manejan su particular estilo con comodidad. Así, Don Quijote funciona, unido al manga, como puente bidireccional entre Japón y España. Fuera de la novela, la universalidad del clásico se abrirá paso hacia la viñeta y hallará su impulso, frente a lo académico, en el ámbito popular.

Palabras clave: Don Quijote; Cervantes; manga; Japón; cultura de masas.

\title{
Don Quijote en el manga: traducción, transformación y adaptación en la cultura de masas japonesa
}

Clara Monzó

Universitat de València
Don Quixote in Manga: Translation, Transformation and Adaptation in the Japanese Mass Culture

During the 19th Century and with the first translations of Don Quixote to japanese, Cervantes' work started to be part of the country's mass culture. As a manifestation of this phenomenon, the manga absorbed the image of the knight-errant. This comic genre adapted it to its aesthetic criteria and merged it with its history and folklore. At the same time, the manga has been exported to Western world, where readers and artists are familiarized with its characteristical style. Hence, Don Quixote works together with the manga as a bidireccional bridge between Japan and Spain. Far from the novel, the universality of this classic will find its way into the drawing and will take as base the popular culture instead of the academic sphere.

KeYwords: Don Quixote; Cervantes; Manga; Japan; Mass Culture. 
Para la inmensa mayoría de los japoneses, la palabra «Don Quijote» no evoca sino una imagen: la de un viejo alto, delgado y loco que, embutido en una anacrónica armadura y sobre un caballo esquelético, se lanza al galope contra unos molinos de viento (Fernández, I985: 20I).

Si, como decía Jaime Fernández, Don Quijote se ha visto reducido a sus significantes visuales, ningún otro género habrá más legítimo que el manga para materializarlo en forma de viñeta. Como parte de la cultura de masas japonesa, el manga se contrapone a la novela desde su conceptualización misma, cuando el peso de la palabra cede su preeminencia a la imagen. ${ }^{\mathrm{I}}$ Recorriendo los vértices donde intersectan estos dos géneros, cabalga el caballero andante como figura simbólica, presto a abordar una nueva hazaña: acercar dos sociedades, dos culturas, distantes. En el camino, se evidenciarán los mecanismos que intervienen en un proceso en el que Don Quijote - personaje y obra- funciona, al mismo tiempo, como producto editorial y como estandarte identitario de la literatura española. Una reescritura que se enfrentará a la traducción a otra lengua, la adaptación a otro género y la transformación de su propio mito.

En el año 2007 la compañía japonesa East Press se embarcaba en un proyecto editorial que ha resultado fructífero hasta la fecha. Agrupados bajo la etiqueta Manga de dokuha; es decir, «leyendo a través del manga», los volúmenes se conciben como clave de acceso a las grandes obras de la literatura universal. Al mercado español llegan a través de la editorial Herder,

I La incorporación léxica actúa aquí como primer indicio de la normalización que ha alcanzado el género en la sociedad española. La RAE registra el término «manga», en función tanto adjetiva como sustantiva, con la acepción de «Cómic de origen japonés». Hasta el momento, anime continúa considerándose un extranjerismo, por lo que a lo largo del artículo aparecerá en cursiva. que ha traducido y publicado en su colección la otra $h$ buena parte del catálogo disponible. Las implicaciones que se desprenden de esta empresa de adaptación a gran escala ahondan en el retrato de una literatura que, proteica, se redefine como artefacto cultural. La voluntad de la editorial por acercar las grandes obras extranjeras al público japonés contribuye a la afirmación de los límites de un canon entendido como corpus, más o menos cerrado, de títulos. Un análisis del listado de la colección permite constatar la ambición de la iniciativa. La aproximación a Occidente toma como buque insignia a Shakespeare, Dostoyevski, Melville o Stendhal pero, a medida que se suceden los números, el escaparate se ramifica, cartografiando un recorrido histórico a través de este conjunto de grandes éxitos.

La fascinación por las naciones extranjeras puede leerse todavía como secuela del periodo conocido como sakoku o "país cerrado». Desde la década de r63o, con la expulsión de la presencia extranjera - fundamentalmente portugueses y españoles-, hasta mediados del siglo XIX, Japón vive este ciclo de aislamiento marcado por la férrea restricción del contacto con Occidente. La llegada en 1853 del Comodoro Mathew Perry a las costas niponas culmina con el inicio de la Restauración Meiji ${ }^{2}$ en 1868 , año que se toma como fecha inaugural. No es de extrañar, tal y como documenta Inamoto (2000) que el nuevo aperturismo fuese de la mano de un deseo de aproximación a las literaturas de los territorios redescubiertos. ${ }^{3}$ Las grandes obras,

2 «El movimiento que ha devuelto al Emperador todos sus derechos políticos, por lo menos en teoría, y las transformaciones políticas y sociales que los han acompañado, son llamados en japonés Meiji ishin (la renovación de Meiji) [...] Se mezclan, de este modo, conceptos nuevos y antiguos, ya que a la vez hay renovación y restauración» (Mutel, 1972: 59).

3 «[...] en esos años Japón pone a trabajar sus máqui- 
con preferencia por Francia y Reino Unido, llegarán a Japón en forma de un torrente de traducciones. Tomando como paralelismo la oferta de East Press, se conforma con ello la urdimbre de una literatura entendida como reflejo de un pensamiento epocal e identitario. En consecuencia, las líneas temáticas se ocupan del género novelístico, pero se diversifican con el mismo empeño hacia el ensayo y las obras filosóficas. Junto a los autores más definitorios de la filosofía occidental como Karl Marx, Kierkegaard, Nietzsche y Kant, este repertorio se atreve también con Sun Tzu, el Corán, la Biblia o el Mein Kampf.

La adaptación se revela como complejo ejercicio de abstracción en el caso de la lírica. Llevar a lo historietístico Une saison en enfer de Arthur Rimbaud o el Paradise Lost de John Milton pone en jaque la definición misma del género poesía. $\mathrm{El}$ interrogante aquí es tratar de dilucidar qué queda del lenguaje específicamente poético una vez se ha volcado en un formato cuyas estrategias estéticas son, en un principio, incompatibles. ¿Es esta adaptación un modo de reconciliar los espacios literarios a golpe de experimentación? Dejando la pregunta en el aire, la cuestión debe centrarse aquí en el propósito primero de la editorial; es decir, la divulgación. La difusión en clave educativa entronca necesariamente con la imperecedera polémica acerca de si es legítimo o no adaptar los clásicos. Baste para ello recordar el último asalto en esta lid protagonizado por la versión para uso escolar del Quijote que la RAE encargó en 20I4 a Arturo Pérez-Reverte. El acercamiento al joven lector

nas a pleno rendimiento para asimilar lo antes posible la cultura occidental. En poco tiempo se construyen edificios a la manera europea, los burgueses cambiarán el kimono por el smoking, los palillos por la cuchara y el tenedor y las editoriales traducirán a gran velocidad (descuidando muchas veces los resultados) a los escritores venidos desde el extranjero» (Cid Lucas, 20II: 218). se equipara en el prólogo del académico nada menos que a una «labor de poda» sustentada en el objetivo siguiente: «a fin de facilitar una lectura sin interrupciones de la trama principal de la novela cervantina, se han retirado del texto original algunos obstáculos y digresiones que podrían dificultar aquella» (Pérez-Reverte, 20I4). La pregunta central a la que conduce esta reflexión sea quizá en qué medida la etiqueta «adaptación» legitima la transformación elástica de la obra.

De todos modos, el índice de East Press, y hay en este fenómeno un giro sintomático, ha incorporado también autores cumbre de la literatura japonesa. Es el caso de, entre otros, Yamamoto Tsunemoto (I659-I719), Natsume Sôseki (I867-I916), Sugita Genpaku (I733-I8I7) o Matsuo Bashô (I644-1694). ${ }^{4}$ El manga no busca servir ya únicamente como mostrador, sino como herramienta de comprensión de un entramado cultural. La publicación conjunta de ambas tradiciones literarias surge de la asunción, por parte de la industria editorial, del manga como producto de consumo más allá de sus fronteras territoriales. Y aquí, partiendo de una consideración del mundo editorial en tanto que motor de mercado, se deslindan una serie de apreciaciones que no pueden disociarse de una aproximación al manga como punto de contacto entre culturas. ${ }^{5}$ Para Koichi Iwabuchi

4 Matsuo Bashô (I644-I694), poeta peregrino, maestro del haiku y autor de libros de viajes compartió, según Montilla Martos, tanto siglo como circunstancias biográficas con Miguel de Cervantes. En esta coetaneidad se apoya el autor para buscar similitudes entre Don Quijote y el correlato de Bashô en sus textos al afirmar que «tanto el hidalgo manchego como el poeta japonés pertenecen a una clase social (hidalgos y samuráis) que poco a poco ha ido perdiendo sus privilegios» (2016: 420).

5 Tras analizar los datos de la JNTO (Japan National Tourism Organisation), Tajada Sanz (2010: 1009) ha puesto en relación la popularidad del manga en Europa con el aumento del flujo de turistas que eligen Japón como desti- 
la cultura de masas funciona como exponente de un doble proceso por el que Japón ha oscilado entre la emulación de la modernidad occidental - Westerization - y la construcción de sus propias señas de identidad (2002). ${ }^{6} \mathrm{El}$ manga se concibe, así, como un puente bidireccional que irradia la literatura japonesa hacia Occidente; y, al mismo tiempo, como puerta de entrada del canon occidental.

East Press selecciona y acomoda al horizonte de expectativas europeo una serie de autores sobre los que proyecta una fotografía a caballo entre el reclamo y la autoafirmación. En consonancia, no es de extrañar que la asignación de la tarea de conectar España con Japón recaiga sobre la obra de Cervantes. En el seno de este catálogo de clásicos, en 2009 ve la luz el tomo Don Quijote de la Mancha. El manga, accesible en español desde apenas 2or6. Decía el escritor Javier Cercas, al identificar a Cervantes como creador de la novela moderna, que la inclasificabilidad del Quijote en el momento de su publicación ha terminado siendo su mayor virtud gracias a «su carácter libérrimo, híbrido, casi infinitamente maleable, el hecho de que es [...] un género de géneros donde caben todos los géneros, y que se alimenta de todos» (Cercas:

no, motivados por ver cobrar vida los emplazamientos que han visto dibujados en las historietas. En cualquier caso, además de la incidencia en el sector servicios, la autora subraya el incremento de la demanda de cursos de japonés y del uso del manga como recurso didáctico en el ámbito de la educación.

6 Remito a este lúcido estudio de Iwabuchi, un análisis de las relaciones entre Japón y Occidente como cara visible de un entramado de dominación, influencia y redefinición de las estructuras nacionales, donde «[...] the transnational intersects with the postcolonial under the influence of the media globalization process» (2002: 53). La búsqueda de la esencia de lo japonés ha desembocado en la revalorización nostálgica de la tradición; hecho que, paradójicamente, despierta el interés del mercado occidental, ávido de productos de entretenimiento que perciba como reflejo estilizado de su folklore histórico.

20II). Si la universalidad del Quijote es un fusor en el que hierven los límites del género novela, se tratará ahora de observar cuál es el grado de incidencia de esa maleabilidad cuando un género fundamentalmente visual como el manga intenta reproducir la magnitud de un clásico narrativo. Pero esto ha de ser el resultado, por un lado, del calado y la popularidad del manga más allá del público japonés y, por otro, de la consolidación de un canon de la literatura universal.

Aparicio Maydeu (2008) considera el Quijote no solo como creador de un género, sino también como punto de partida para entender el surgimiento de la ficción contemporánea. Desde esta óptica, la obra se habría visto desposeída de sí misma y sería, desde luego, mucho más que una imagen. Como sentenciaba Harold Bloom, "No two readers ever seem to read the same Don Quixote» (1995 [1994]: I28). La ficción quijotesca se vuelve espacio; un universo moldeado por la exégesis y emergente a través de cada una de las reescrituras que participan - a través de una herencia no necesariamente autoconsciente - en, y de, la expansión de su núcleo.7 La conjunción de las premisas anteriores evidencia el alcance de una globalización que ha permitido el trasvase intergenérico y transcultural a través un género que se nutre de la cultura de masas. Para Rodríguez Fernández (2or6), manga y anime han trascendido como motor de una industria del entretenimiento que permite combinar la proyección de unos valores propiamente folklóricos o costumbristas con la

7 En su celebérrimo ensayo, Bloom hacía equivaler a Hamlet y al Quijote en el merecimiento de la inmortalidad, si bien trasladaba el centro del canon literario del español al dramaturgo inglés: «[...] only Cervantes and Shakespeare occupy the highest eminence; you cannot get ahead of them, because they are always there before you» (I995 [1994]: 128). Una admiración que, si atendemos a la recepción de ambas obras, los japoneses parecen compartir con Bloom. 
espectacularidad de los recursos de animación atractivos a las industrias de producción internacionales. Que autores argentinos aborden la publicación de un manga desde un territorio tan alejado de Japón, supone la cristalización de este contacto, un caso en el que me detendré más adelante. En la era de la inmediatez, en este proceso de globalización, es la cultura de masas y no los agentes del ámbito académico la que ha dinamitado el establecimiento de Japón como foco de interés. ${ }^{8}$

La visualización del manga y del anime, si bien disponibles en la mayoría de establecimientos y cadenas comerciales en formato físico, alcanzan su difusión en internet, donde grupos de voluntarios se aplican a la traducción de las obras, a cuya lectura puede accederse sin coste alguno. Precisamente la circunscripción de manga y anime a la cultura de masas los aleja en España de los focos de crítica de corte más intelectual. Exceptuando las voces más simbólicas, como el director Hayao Miyazaki o el dibujante Jiro Taniguchi que, indiscutiblemente, han alcanzado reconocimiento mundial, la consideración de la animación japonesa por su valor artístico continúa lastrada por su adscripción a la industria del entretenimiento. Eco de ello se hace Montero Plata al evidenciar «la falta de herramientas de la prensa española para catalogar y dialogar con las obras animadas sujetas a estudio. El mercado de la anima-

8 El proceso de asentamiento del manga en Estados Unidos alcanzó su punto álgido en la década de los 2000 con la adaptación al inglés de la revista manga Shonen Jump como fruto de un acuerdo comercial entre las editoriales Shûeisha y Viz Media. Orientada al público joven masculino, esta publicación, originalmente semanal, pasó a distribuir con periodicidad mensual series del momento como $Y u-G i-O b !$ o One Piece cuya difusión se nutría, a su vez, de la popularidad del anime (Bainbridge y Norris, 2010). En Europa, Francia es el primer importador de manga y anime; por delante de Estados Unidos a nivel mundial (Montero Plata, 20II: I022). ción es todavía muy reducido y la entrada del anime incipiente si la comparamos con otros países europeos» (2011: I03I). Volviendo por un momento al caso de Taniguchi, su muerte en febrero de este mismo año trascendió a los medios de comunicación escrita, que lo elogiaban significativamente por ser «autor de clásicos del manga» $(E F E, 20 I 7)$ o por "convertir historias cotidianas en universales con un dibujo perfecto» (Altares, 20I7).

Reagrupando los elementos anteriores, Don Quijote se erige -en tanto que narración o personaje- más allá de lo estrictamente literario, como imagen estandarte del retrato doméstico listo para la exportación. La llegada del caballero a Japón se remonta a aquel año de I868, cuando la obra de Cervantes desembarca y se difunde en territorio nipón acompañando a Shakespeare y a Molière. La producción cervantina se abre camino en este mundo que acaba de re-descubrirse a sí mismo protagonizando un periplo de traducciones. La indagación en esta trayectoria constituye el punto de partida para comprender el modo en que se ha absorbido, desde Japón, el representante del canon cultural español, así como el alcance de esta absorción en la sociedad contemporánea.

El contacto previo entre España y Japón se había producido por medio de los jesuitas, desde que en 1549 el misionero navarro Francisco Javier (1506-1552) desembarcase en Kagoshima; un contacto que se ve progresivamente interrumpido con la cruda persecución al cristianismo iniciada en la recta final del siglo Xvi. ${ }^{9}$ Cuando los ecos de las aventuras del caballero

9 Para ahondar en las figuras de Francisco Javier y Cosme de Torres (I510-1570) y la presencia de los Compañía de Jesús en Japón, véase el trabajo de Lisón Tolosana (2005). Puede consultarse, como testimonio a caballo entre lo literario, lo documental y lo propagandístico, la obra de Lope de Vega Triunfo de la fee en los reynos del Japón por los años de I6I4 y I6I5, publicada en I6I8. 
andante tuviesen la oportunidad de llegar a la isla, habrían pasado, por lo tanto, más de 200 años desde la publicación del primer Quijote. ${ }^{\circ}$ 40
En los orígenes de la odisea editorial, las dos primeras traducciones corresponden a sendos títulos de las Novelas ejemplares: El casamiento engañoso, bajo el título de Historia europea de los amores de una mujer hermosa [Oushu Jowa Tanamara], en I885; y, en 1887, La fuerza de la sangre, traducida como Otra historia europea del ruiseñor en el valle [Oushü Shinwa Tanima no Uguisu]. En ambas, Cervantes se ha transformado en "Cervanto», un autor de nacionalidad francesa.

En cuanto al Quijote, en 1887 aparece una publicación parcial por entregas que queda inconclusa, aunque constan referencias a la presencia del Quijote en Japón en 1867. Poco después, en I893 se publica en dos tomos la primera traducción al japonés de la Primera Parte, a cargo de Shouyou Matsui y bajo el título de Donquiou bouken tan o Historia de las aventuras de un viejo gracioso de poco ingenio. La fuente directa de esta y las siguientes cuatro traducciones de la última fracción del XIX no será el texto original, sino la versión en inglés. La Segunda Parte quedará desterrada del campo editorial hasta que, al fin, en 1958 y 1962 un Quijote completo en dos tomos ve la luz a cargo de Yû

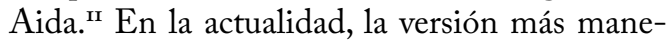
jada entre estudiantes y lectores en general es,

Io Jaime Fernández — cuya labor documental ha seguido completando Cid Lucas- continúa siendo el referente para la indagación en la senda textual del Quijote y la recepción de la crítica en Japón. Remito a ambos - Fernández (1985) y Cid Lucas (20II) — para fechas, títulos y una ampliación detallada de las distintas traducciones de la obra cervantina que aquí esbozo de forma somera.

II No confundir a este Yû Aida (I903-I97I) —intelectual, profesor de literatura, «traductor y entusiasta investigador de Cervantes» (Fernández, I985: 202) — con el mangaka contemporáneo Yû Aida, creador del manga Gunslinger Girl (2002-2012). siempre de acuerdo con Cid Lucas, la traducida en 2004 por Katsuyuki Ogiuchi:

Ogiuchi dijo de ella en una memorable entrevista que «se podría leer como un manga», frase en la que unía (como es costumbre en Japón) la tradición centenaria de la novela cervantina y la más candente actualidad de la nación, simbolizada ésta por el manga o el anime, tan de moda ya tanto en Japón como en Occidente (20Ir: 219).

Así pues, el flujo de estudiantes y la inmediatez propia del intercambio cultural del siglo XxI ha favorecido la difusión de la obra más allá del ámbito académico. ${ }^{\mathrm{I2}}$ Este hecho puede quizá explicarse con las siguientes palabras del crítico, que afirma: «un personaje como Don Quijote jamás podría ser un ejemplo a seguir entre el pueblo nipón, ni aún [sic.] bebiendo de su lado más romántico o idealista, opuesto en todo a la moral neoconfuciana que durante muchos años imperó en Japón»³ (20II: 215). Así se comprende que un personaje que antepone sus ideales a las obligaciones marcadas por el orden social se haya visto confinado durante décadas a los espacios reservados, en el ámbito de la industria del entretenimiento, al público infantil. Entre los años 70 y 90 se produjo una oleada de animaciones japonesas que bebían de la estela divulgativa y apostaban por las posibilidades educativas de la televisión. La compañía Nippon Animation es la responsable de la importación a Europa de series como Heidi (1974), Marco (1976) o

I2 Más tajante se muestra Jaime Fernández al afirmar que «El lector japonés es más bien una víctima de la inexplicable falta de interés de los intelectuales del país respecto a Cervantes y su obra» (1985: 205).

r3 Okubo (2005: 152) aporta, en cambio, una visión contraria: «[...] precisamente por ser una sociedad tan uniformada en la que todos van como patos en fila, el héroe en Japón, en la historia y en las artes, sobre todo en las artes marciales (Budo), ha sido el «Ippiki Okami» (el lobo solitario), el que actúa sólo por sus ideales, no como miembro o en beneficio del grupo o la sociedad». 
Pollyanna (1986), que calaron en el imaginario popular de varias generaciones de espectadores. En este marco, en 1980 Ashi Productions lleva a la pantalla una serie de 23 episodios llamada Zukkoke Knight: Don de la Mancha. ${ }^{\mathrm{I}}$ Desenfadada, colorista y poco rigurosa, esta emisión convierte a Don Quijote en un ser zoomorfo, vagamente parecido a un perro, cuyos intentos alucinados por complacer a una pícara Dulcinea buscarán provocar la risa entre el joven público.

En cierto sentido, el manga de East Press - recordemos, traducido y distribuido en España por la otra b- reproduce todavía estos parámetros al favorecer la recepción de la obra desde una perspectiva humorística. El volumen se articula en ocho capítulos que condensan, a lo largo de 200 páginas, la primera y la segunda parte de la obra. En apéndice incluido al final del manga, se expone un sucinto análisis contextual encaminado a esbozar un panorama básico de las interpretaciones y la recepción de la crítica, recalando fundamentalmente en las Meditaciones del Quijote de Ortega y Gasset (I9I4). La dimensión profunda a la que se apunta en este anexo no se corresponde, sin embargo, con el planteamiento del manga, pues Don Quijote aparece como un hombre trastornado por la literatura de caballerías cuya fijación por la compra de libros ha provocado la ruina de su familia. El desarrollo de las, más que aventuras, desventuras, se dilata en la presentación del

I4 La serie se televisó en varios países de Latinoamérica bajo el nombre de Don Quijote y los cuentos de la Mancha. En internet, algunas fuentes apuntan a $\mathrm{La} 2$ como distribuidora en España, pero no he logrado contrastar la referencia. Resulta altamente recomendable el visionado del opening, donde un divertido coro de animales entona «Don de la Mancha, Don de la Mancha» mientras el héroe corre sobre el anillo de Saturno, ¿quizá como metáfora de la universalidad de Don Quijote? Por otra parte, existe una serie de 2I capítulos emitida en I965 llamada Donkikko cuya relación con la obra cervantina no parece extenderse más allá del nombre del protagonista. protagonista, definido en torno a la locura y el conflicto con su círculo social. De inmediato, tras la incorporación del escudero, acontece el episodio de los molinos y, en apenas tres páginas, el enfrentamiento con el rebaño de ovejas, la liberación de los galeotes y la adquisición del yelmo de Mambrino. Hasta aquí, la breve muestra funciona como enumeración jocosa de las andanzas y se sustenta en el empuje de la confusión dicotómica entre realidad y fantasía.

El imperio de la comicidad es, no obstante, lo que desdibuja la motivación de los personajes y simplifica el extraordinario juego metatextual que opera en el paso de la Primera a la Segunda Parte. También la ambientación se permite ciertas licencias y no vacila a la hora de encajar anacronismos, como sucede con en el atuendo del ama o algún divertido guiño que introduce objetos contemporáneos. Ni rastro de la amistad y la llana inocencia de un Sancho que azuza las visiones de su señor, movido exclusivamente por la jugosa promesa de la ínsula. El comportamiento errático de Don Quijote es objeto ya no solo de burla, sino de reprobación, por parte de los personajes secundarios. Las acciones de estos, lejos de contribuir veladamente a la construcción de la figura del héroe, ponen su empeño en hallar la cura para la enfermedad literaria, que se ve reducida al capricho fortuito del protagonista.

Pero la elección del manga en sí misma evidencia las ramificaciones de este fenómeno de apropiación de los géneros japoneses, en el seno de las manifestaciones de la cultura de consumo popular. ${ }^{15}$ Para Bainbridge y Norris

I5 Rodríguez Fernández establece una red relacional que tiene al anime como centro y que conecta, más allá de la industria editorial, con los videojuegos, la música y la generación de merchandising. Seguidor y consumidor se confunden en una misma figura: «Sin duda, el consumo que podríamos llamar "fan", resulta atrayente para cierto número de empresas que ven en este target un público con 
(2010), el manga moderno hace visibles sus estrategias narrativas como producto de una deliberada táctica de mercado que facilite su apropiación por parte de industrias extranjeras. Aquí puede traerse a colación el Don Quijote en dos volúmenes que Federico Reggiani y Sergio Coronel publicaron en la editorial Moebius en 2008 y 2009 respectivamente. Entendido el manga como exponente de una escuela de técnica pictórica enraizada en la identidad nipona, supone un paradigmático ejemplo de intercambio, inserto en el fenómeno de transculturación literaria. El resultado de este Quijote argentino será, por lo tanto, un artículo híbrido:

$[\ldots]$ in dealing with the key cultural and economic dimensions of this flow, two key propositions have emerged. The first is that the worlwide dissemination of Japanese media marks a new form of cultural imperialism or "soft power" from Japan. The other is that these products are already somewhat hybridized and therefore familiar to a globally dispersed audience rather than representing or promoting a unitary idea of "the Japanese lifestyle" or ideals (Bainbridge y Norris, 2010: 24I).

De entre los recursos propios de la tradición occidental, la elección se efectúa en favor de un género historietístico extranjero importado cuyos presupuestos estéticos se siguen con fidelidad. ${ }^{16}$ Los elementos paratextuales de este

poder adquisitivo capaz de pagar unos precios elevados por ciertos productos. Gamers, otakus, cosplayers, etc., son un nuevo estilo de consumidor que se ve sustentado por este tipo de producciones» (2016: 186). En otra perspectiva, el teatro japonés ha subido a Don Quijote a sus tablas, tal y como documenta Okubo (2005). La autora, además de las versiones niponas del clásico musical Man of la Mancha, se hace eco de propuestas de corte más experimental a través del ejemplo de la compañía Ksec ACT. Ávidos adaptadores de la dramaturgia europea, su última visita a España trajo consigo en 2014 El caballero de Olmedo.

${ }_{16}$ Mayores implicaciones observan Bainbridge y Norris en esta globalización del manga, que consideran expo- manga se suman a un proyecto que parte de una originalidad consciente. En las primeras páginas Cide Hamete Benengeli firma, desde Okinawa, un prólogo en el que se dirige al lector $\mathrm{y}$, a modo de captatio benervolentiae, le ofrece la obra apelando a la contemporaneidad del clásico como legitimación de su paso a las viñetas: «E1 Quijote siempre fue un libro de su tiempo, de todos los tiempos. Y si el manga nos trae de Japón el lenguaje de las risas y las aventuras de hoy, qué mejor que vestir de manga las viejas aventuras» (2008: 3). El primer volumen emula la estructura del libro áureo con la inclusión de tasa y testimonio de erratas. Se logra así mantener una experiencia doble para el receptor, que puede lanzarse a la lectura del manga con cierto conocimiento acerca de la materialidad del original en tanto que producto de imprenta.

Sobre los anteriores matices, el enfoque de esta adaptación no dista de la de East Press, al situar el humor como el elemento dominante; en palabras de los autores: «En esta versión al estilo manga hemos querido ser muy fieles al libro original, y por eso hicimos una comedia y un libro divertidísimo» (Reggiani y Coronel, 2008). En virtud de esta fidelidad, la recreación del sigo XVII encierra un trabajo documental que se hace patente a través del diseño y el habla de los personajes. ${ }^{17} \mathrm{El}$ cruce de dimensiones tex-

nente de una «desnacionalización de contenido» [denationalization of content]. La caracterización de los personajes en el estilo del manga juega a favor de una ambigüedad tanto étnica como sexual donde «Japanese manga artists can easily soften, erase, or replace a character's Japaneseness» (2010: 246).

${ }^{17}$ En el artículo de Cid Lucas se incluye ya una breve mención al manga argentino, del que solo el primer volumen se había publicado. $\mathrm{Al}$ respecto de la ambientación, el autor resalta ciertas desviaciones y opina que «[...] ambos creadores han jugado con algunos tópicos españoles, como el hecho de que Sancho Panza marche de una aventura a otra ataviado con un atuendo andaluz (sombrero cordobés incluido), algo que se corresponde poco con el traje típico manchego de aquella época, pero que cualquier lector, 
tuales que se esquivaba en el manga japonés se exprime aquí no solo como reconocimiento de la genialidad del autor, sino como reclamo del interés del lector. Retomemos por un momento el capítulo Ix de la primera parte: Don Quijote y el vizcaíno, espadas en ristre, se disponen a entrechocar las armas cuando de súbito la narración queda suspendida por la intervención del mismo Cervantes, que confiesa apesadumbrado desconocer su desenlace. La traslación al dibujo de este instante detenido en el tiempo es sumamente efectiva, pues reconduce el suspense y muestra a los caracteres como actores a la espera de instrucciones. Los narradores - pues Reggiani y Coronel no dudan en apropiarse de la voz del relato - toman la resolución de «consultar con Don Miguel» la continuación del pasaje. Es así como en las ilustraciones siguientes Cervantes, convertido en personaje, participará en la creación de su héroe y, estando un día en Alcalá de Toledo, hallará por medio de un muchacho los cartapacios de Cide Hamete Benengeli.

Del mismo modo que se conserva el celebérrimo «En un lugar de la Mancha» como oración inaugural, el espectro de episodios seleccionados constituye un representativo muestrario de las andanzas del caballero. Más allá de los molinos, amo y escudero conocen a Maritornes en la venta, hacen correr la sangre de unos cueros de vino y padecen los estragos estomacales del bálsamo de Fierabrás. El segundo volumen toma el relevo con la ruidosa amenaza de los batanes y decide no dejar de lado alguno de los arcos parentéticos de la obra. El foco del relato abandona al héroe durante buena parte del tomo para ceder el protagonismo al enredo amoroso de Cardenio y Dorotea, cuyo destino

oriental u occidental, identificará rápidamente con nuestro país» (201r: 224). queda entrelazado con el de Don Quijote al transformarse en la princesa Micomicona.

Más allá de refranes y chascarrillos, en ambos mangas el destierro de la seriedad afecta a la plasmación del desenlace cervantino. Así como se había pasado de puntillas sobre el escrutinio de la biblioteca, se buscan ahora soluciones alternativas que permitan omitir la muerte de Don Quijote. En el caso argentino, la conclusión se resuelve en clave de aventura con un remedo del clásico "continuará», que culmina con el ingenioso hidalgo enjaulado, de vuelta a casa. Si bien se había perfilado la trama en su hondura laberíntica, no llega a producirse la inversión de papeles de la segunda parte en que los personajes secundarios pasan a ser los responsables de aguijonear los disparates del caballero, que termina convencido de serlo. Al fin y al cabo, tal y como afirman Reggiani y Coronel (2009) en el segundo volumen: «Ahora el espectáculo completo queda en manos de lectoras y lectores con ganas de pasarla bien».

En el Manga de Dokuha, el bachiller Sansón Carrasco asume las características del auténtico héroe al transformarse en el Caballero de los Espejos y tratar de derrotar al protagonista descarriado para forzarlo a volver a casa. La conversión final se produce, sin embargo, cuando el Duque ordena caballero a Don Quijote y este, una vez ha visto mundanizada su utopía, recupera súbitamente la cordura. $\mathrm{Al}$ producirse el reconocimiento de la locura artificial, esta es mostrada al lector como una mera consecuencia del aburrimiento de un hidalgo rural, arrastrado por sus ensoñaciones. Se fuerza así una confesión de Don Alonso - que ya no Don Quijote- en la que se retracta de sus acciones, volviendo arrepentido al redil del «fuese y no hubo nada».

En ambos mangas, la obra -o, más bien, el personaje cervantino- actúa como un reci- 
piente en el que intersectan lejanas coordenadas histórico-literarias. Desde el punto de vista plástico, el diseño se ajusta a un dinamismo en el que la abundancia de onomatopeyas, líneas de movimiento y el expresionismo hiperbólico de los personajes subrayan la combinación ágil de aventuras y comedia. El formato del producto resulta cómodo al lector, pues permite sortear la complejidad de una obra que se percibe como amenazante. Como curioso exponente de la reconfiguración del género, ambas editoriales han apostado en su presentación por ajustarse al sentido de lectura occidental; es decir, de izquierda a derecha, y se pierde con ello algo de la esencia de la experiencia de lectura del manga. Entroncando con la controversia sobre las adaptaciones al receptor novel, este caso se suma a la doctrina del best-seller. Queda aún por dilucidar si este tipo de producto funciona como un primer acercamiento a los clásicos a fin de facilitar la profundidad de un segundo asalto o si, por el contrario, el lector dará por satisfecha su curiosidad. Más aún, queda por analizar la recepción del manga del Quijote por parte del público español mismo. Si se rastrean las reseñas que circulan por internet al respecto de la colección de East Press, pueden encontrarse comentarios del siguiente calibre: «En un contexto en el que las Letras atraviesan un periodo incierto, las imágenes vuelven al rescate, tratando de valer, de nuevo, más que mil palabras» (Luque García, 20I3)..8

Una vez más, se contrapone el calado de la imagen frente a la aspereza de la palabra. Que la imagen puede adoptar distintas máscaras

I8 En esta reseña trasluce la búsqueda de sustitutos ante la percepción de los clásicos como un deber al que hay que acercarse por presión social: «Crees en su carácter de "grandes obras" sólo porque alguien te las recomendó o en clase te decían que eran buenísimas - "Hola, soy tu libraco del Quijote"-. Pues bien, Japón tiene una solución» (Luque García, 2013). lo demuestra el tercero de los manga, Haikai Roujin Don Quixote; en español, Un viejo errante Don Quixote de la Mancha. ${ }^{19}$ En 1936 había aparecido en Kyoto Ehon Don Kihote, un álbum con un conjunto de ilustraciones firmadas por Keisuke Serizawa (I895-I984) e inspiradas en pasajes del Quijote. Considerado por Fernández como «artista intérprete» (1985: 207), Serizawa muestra a un hidalgo japonizado que, ataviado al estilo tradicional nipón, cabalga sobre campos de bambú. ${ }^{\circ}$ Por mucho que, entonces, el propio Fernández redujese la percepción de Don Quijote en el imaginario popular japonés a una imagen, esta no dejará de ser susceptible de reformularse de acuerdo con los modelos estéticos nativos. ${ }^{21} \mathrm{Al}$ igual que el artista, Haikai Roujin Don Quixote no persigue el objetivo costumbrista de reflejar estéticamente la sociedad de la España cervantina sino que busca su impulso en otras bases. El énfasis se ha trasladado desde la forma hasta la esencia, en la composición de un protagonista que ha liberado a Don Quijote de su cáscara. La confianza en el significado otorga a su autor, el mangaka Kotobuki Shiriagari, el albedrío para actualizar los significantes.

El viejo errante se cimenta sobre la vertiente más romántica de Don Quijote, la del héroe que se sabe un auténtico caballero cuyo ideal se mantendrá inalterable: «enderezar tuertos».

19 Publicado entre 20I0 y 20II, sus nueve capítulos se reúnen en un solo volumen, incluidos prólogo y epílogo. Este manga no se encuentra, hasta la fecha, traducido al español. Sigo, por lo tanto, la versión en inglés, solo disponible en red.

${ }_{20}$ En la línea de la obra de Serizawa, la artista $\mathrm{Ma}-$ ría Expósito Santiso realizó una magnífica serie de doce litografías reunidas en 2004 bajo el nombre de El Quijote samurái y editadas por Summa editorial.

${ }_{\text {2I }}$ Por otra parte, existe por lo visto en Japón una gran cadena de tiendas de saldos llamadas Don Quijote [http:// www.donki.com/en/]. Contra todo pronóstico, la mascota de la superficie es un simpático pingüino azul. 
Es esta meta, precisamente, la que ha ejercido de anclaje sólido en la convergencia literaria de España y Japón y ha encontrado correspondencias entre el héroe cervantino y la figura del samurái. ${ }^{22}$ La analogía se asienta tanto en el paralelismo de una élite militar vocacional venida a menos como en la materialización del ideal ético impuesto a la realidad observable. Tal y como sostiene Martínez de Lara: «El kanji de la palabra samurái encarna la misma vocación de servicio, el mismo código de honor y el mismo camino de perfección que encierra el pensamiento de don Quijote» (20I6: II2). En este estudio, selecciona pasajes del Quijote para aplicar las reglas del bushido, el camino del guerrero por el que se rige el samurái. De entre las siete virtudes que conforman este código - justicia, coraje, benevolencia, respeto, honestidad, lealtad y honor- es la última, el meiyo, la que justifica la vinculación en mayor medida. Siguiendo su dictado, el samurái indaga y ve aflorar su individualidad a partir de la experiencia sufriente de los obstáculos vitales.

Bajo estos parámetros pueden interpretarse las acciones del viejo errante de Shiriagari. Los paisajes de la Mancha se han sustituido aquí por las calles de cualquier ciudad actual de la región de Kanto, un universo urbano que sigue el dictado de la inmediatez y la productividad. Frente a

${ }^{22}$ No solo en el samurái encuentra equivalencias el famoso hidalgo. En 2010 vio la luz la primera superproducción cinematográfica china en ${ }_{3} \mathrm{D}$ cuyo título es, precisamente, Don Quixote. Abril Sánchez analiza los entresijos de esta adaptación del director Ah Gan tomando como modelo El arte de la guerra del célebre estratega Sun Tzu: «In his enterprise, Chinese Don Quixote's conduct seems to have many things in common with that of his Spanish counterpart, as the medieval knight's code does not differ much at first glance from the Chinese discipline of swordplay. Indeed, Ah Gan manages to blend the two cultures into an interesting figure, which stands out for its combination of chivalrous idealism and delusional foolishness» (20I0: IIO). pastores y bandoleros, en estas páginas el léxico refleja el argot nocturno de los adolescentes o la jerga empresarial de ejecutivos en contraste con el habla de otro tiempo del viejo. Este peculiar Don Quijote viste, en cambio, una humilde yukata y sandalias zōri; y exhibe sobre su cabeza un kabuto, un casco propio de la vestimenta tradicional militar adoptado por los samuráis como parte de su equipamiento. Así, se logra el mismo desajuste entre el atuendo anacrónico del protagonista y el resto de personajes que en la obra original. El kabuto, que podía confeccionarse como objeto de elaborada belleza y cuya estructura alcanzaba complejas combinaciones, queda aquí reducido, cual bacía, a su forma más sencilla. Es la mirada del viejo errante la que transforma tanto su apariencia como la realidad que habita.

Clasificado bajo la etiqueta de comedia, no se excluyen en este manga los equívocos provocados por una perspectiva alucinada que pasa de trocar Aldonza y Dulcinea a confundir a su amada con el celador de un bloque de edificios. En su conjunto, el manga no se concibe como una adaptación, sino que se apropia de Don Quijote en tanto que figura heroica destinada a evidenciar las fisuras de la contemporaneidad. Poco a poco se va exponiendo el pasado trágico de la figura principal que fue, antes de enloquecer, el director de una importante empresa. En este dramatis personae, Sancho hace las veces de abogado y enfermero, encargado de vigilar a su escurridizo cliente. Sus aventuras están marcadas por el afán de perseguir demonios, ya sea en el vagón del metro, entre un grupo de estudiantes de instituto o escondidos en un monstruoso depósito de agua.

El dibujo se ha sometido también a cierta renovación y se aleja del estilo manga más cuadriculado. Las líneas se vuelven fluidas y acalambradas, creando una atmósfera de expre- 
sionismo crispado que influye en la disposición anímica del lector y enfatiza el frenetismo de la sociedad japonesa. Para ello, se aparta del enfoque mimético e inserta escenas que beben de la dimensión más irracional del surrealismo a fin de retratar la sociedad japonesa - en realidad, cualquier sociedad amoldada a los resortes capitalistas - como una única psique colectiva que se mueve con el impulso de un autómata. Occidente no ha conseguido cortar el pelo de este Don Quijote, que pasea empuñando su lanza por un mundo que siente la obligación de salvar. En el centro de este cosmos, lo cómico se vuelve pronto tragicomedia y, al tiempo que el lector compadece al anciano enfermizo, no puede dejar de ver en su locura un alarde de lucidez liberadora.

En el extremo opuesto de Haikai Roujin Don Quixote, la última propuesta llega con Ureigao no kishi sono ai, El caballero de la cara triste y el amor, editado entre 2013 y 2014 en la publicaciónComic@Bunch del grupo Shinchosha. No disponible en el mercado español y aún por traducir, este manga parece acercarse por su estética al subgénero del shoujo. ${ }^{23} \mathrm{~A}$ la espera de poder examinar el apartado textual, la plasmación plástica de los personajes elabora un par protagonista alejado de los anteriores ejemplos; pues Don Quijote es aquí un apuesto joven de larga coleta que se hace acompañar por Sancho, un niño rubio. Las viñetas muestran al héroe en sus dos ambientes prototípicamente definito-

23 El manga se escinde tradicionalmente en multitud de subgéneros que se ajustan a distintos criterios; por lo general, la temática. En este caso, el shoujo, manga destinado a un público joven femenino, se opone al ya mencionado shonen, orientado a público masculino. Aunque estas fronteras parecen estarse difuminando, la clasificación por sexos continua plenamente vigente en la cultura de manga $\mathrm{y}$ anime. No me ha sido posible encontrar una traducción de este manga, por lo que baso este breve análisis exclusivamente en la observación de los elementos estéticos. rios: rodeado de libros en un ordenado estudio y ejercitándose incansablemente cual guerrero esforzado. Lejos de la vertiente ostentosamente cómica del primer manga, aquí impera una estilización que contiene la expresividad de las facciones y vuelve nítidos los contornos, dibujando los espacios con detallismo armónico. Queda por esclarecer si este caballero andante es objeto de burla o un atormentado héroe romántico; mientras, las ilustraciones nos muestran, al menos, cómo todo auténtico Don Quijote se verá cautivado por su noble ideal. Así, tras vestir la armadura, el primer capítulo finaliza con una imagen que se extiende hacia el horizonte y muestra la figura de dos jinetes que, cabalgando sobre caballo y jumento, se alejan hacia ninguna parte.

Ya sea entonces convertido en joven gallardo, en un viejo cascarrabias que deambula por Tokio o conservando, cual yelmo prodigioso, su bacía de barbero, Don Quijote continúa combatiendo molinos alrededor del mundo. En el proceso de acercamiento a Japón, el caballero andante se ofrece con la ductilidad de un clásico, complacientemente dispuesto a adaptarse a nuevas coordenadas. Imagen y palabra, su incursión en el género del manga contribuye doblemente a la consolidación de su figura como representante del canon literario español y a la difusión de su mito entre los lectores consumidores de la cultura de masas.

RECIBIDO EN JULIO DE 2017

ACEPTADO EN JULIO DE 2017

VERSIÓN FINAL DE OCTUBRE DE $20 I 7$

\section{BIBLIOGRAFÍA}

Abril Sánchez, Jorge (2013): «Ah Gan's Don Quixote (魔俠傳之唐吉德, 20I0): Sun Tzu, Sun Bin, and the Warrior Spirit of the Chinese Knight of La Mancha» en Matthew D. Warshawsky y James A. Parr (eds.), Don Quixote: Interdisciplinary Con- 
nections, Newatk, Delaware: Juan de la CuestaHispanic Monographs, IO7-I35.

Altares, Guillermo (20I7) «jiro Taniguchi, el dibujante que rompió las barreras del manga», Babelia, El País, I4 de febrero, <http://cultura.elpais.com/cultura/2OI7/O2/I3/actualidad/I486987984_954207. html>.

Aparicio Maydeu, Javier (2008): Lecturas de ficción contemporánea: de Kafka a Ishiguro, Madrid: Cátedra.

Bainbridge, Jason y Norris, Craig (20I0): «Hybrid Manga: Implications for the Global Knowledge Economy» en Toni Johnson-Woods (ed.), Manga: An Anthology of Global and Cultural Perspectives, New York: Continuum, 235-252.

Bloom, Harold (1995 [1994]): The Western Canon. The Books and School of the Ages, London: Paperman.

Cercas, Javier (20II): «La tercera verdad», Babelia, El Pais, 25 de junio, <http://elpais.com/diario/20II/o6/25/babelia/1308960747_850215.html>.

Cid Lucas, Fernando (20II): «Llegada y recepción del Quijote en la literatura y en la cultura popular japonesa» en Christoph Strosetzki (coord.), Visiones y revisiones cervantinas: actas selectas del VII Congreso Internacional de la Asociación de Cervantistas, Alcalá de Henares: Centro de Estudios Cervantinos, 215-226.

Don Quijote de la Mancha. El manga [Manga de dokuha, Don Quixote] (2016 [2009]): Marta E. Gallego Urbiola (trad.), Barcelona: Herder.

Fernández, Jaime (I985): «Cervantes en Japón», Anales Cervantinos, 23, 20I-2I2.

Inamoto, Kenji (2000): «Don Quijote convertido en samurái: adaptación cultural en los primeros intentos de traducción al japonés del "Quijote” en Antonio Bernat Vistarini y José María Casasayas (eds.), Desviaciones lúdicas en la crítica cervantina. Primer convivio internacional de "Locos Amenos»: Memorial Maurice Moblo, Salamanca: UIB-USAL, 305-310.

Iwabuchi, Koichi (2012): Recentering Globalization: Popular Culture and Japanese Transnationalism, Durham: Duke University Press.

Kawata, Yushi y Yukito (20I3-20I4): Ureigao no kishi sono ai [El caballero de la cara triste y el amor], Japón: Shinchosha.

Lisón Tolosana, Carmelo (2005): La fascinación de la diferencia. La adaptación de los jesuitas al Japón de los samuráis, 1549-1592, Madrid: Akal.
Luque García, Ander (2013): "Manga de Dokuba: Japón al rescate de las letras universales», PliegoSuelto, 29 de mayo, <http://www.pliegosuelto. com/?p=6537> [consulta: $10-V-2016]$.

Martínez de Lara, Ángel (20I6): «Virtudes del Bushido en el Quijote» en Emilio José DelgadoAlgarra (ed.), Occidente en Japón y Japón en Occidente: claves cientificas, educativas y culturales para el intercambio entre Japón y Occidente, Huelva: Universidad de Huelva, Io9-I22.

Montero Plata, Laura (20II): «Animación japonesa bajo una mirada occidental», en Elena Barlés Báguena, y Vicente David Almazán Tomás (coords.), Japón y el mundo actual, Zaragoza: Prensas Universitarias de Zaragoza, Ior3-IO34.

Montilla Martos, Ángel Luis (20I6): "Caballeros y monjes ante la injusticia: Cervantes y Matsuo Basho», Anjhara Gómez Aragón (ed.), Japón y "Occidente»: El patrimonio cultural como punto de encuentro, Sevilla: Aconcagua Libros, 417-420.

EFE (2OI7): «Muere el japonés Jiro Taniguchi» (20I7), $A B C$, II de febrero, <http://www.abc.es/cultura/ abci-muere-japones-jiro-taniguchi-poeta-manga-201702II2OI3_noticia.html .

Mutel, J (1972): Japón. El fin del shogunato y el Japón Meiji I853/I9I2, trad. M. Batllori, Barcelona: Vicens-Vives.

Okubo, Michiko (2005): «Don Quijote, un héroe ideal para Japón», ADE teatro, I07, I52-157.

Pérez-Reverte, Arturo (2014): «Prólogo» a Miguel de Cervantes, RAE (ed.), Don Quijote de la Mancha [edición escolar adaptada], Madrid: RAE/Santillana.

Reggiani, Federico y Coronel, Sergio (2008-2009): Don Quijote, Buenos Aires: Moebius, v. I y 2.

Rodríguez Fernández, Iván (2or6): «El anime como valor cultural» en Anjhara Gómez Aragón (ed.), op. cit. , $183-193$.

Shiriagari, Kotobuki (2000-200I): "The Wandering Senior” Don Quixote [徘䧃老人”ドン・キホーテ. Haikai Roujin Don Quixote], trad. Hox, Japón: Asahi Shimbunsha.

Tajada Sanz, Cristina (20II): «Intercambios culturales entre Japón y España a través del manga», en Barlés Báguena, y Vicente David Almazán (coords.), op. cit., IOOI-IOI2. 